\title{
PERANCANGAN APLIKASI SECURITY LOCK BERBASIS ANDROID
}

\author{
Sri Mardiyati ${ }^{1}$, Lusi Ariyani ${ }^{2}$ \\ ${ }^{1,2}$ Informatika Universitas Indraprasta PGRI \\ srimardiyati05@gmail.com¹, lusiariyani0312@gmail.com²
}

\begin{abstract}
Abstrak
Aktivitas - aktivitas ini tentunya akan melakukan pertukaran informasi di dalamnya. Oleh karena itu smartphone biasanya telah dilengkapi fitur keamanan agar informasi tidak tersebar secara bebas. Di era teknologi ini, diperlukan keamanan data. Salah satu cara untuk mengamankan gadget kita dengan menggunakan sistem aplikasi seperti tombol, pin lock, pattern lock, serta sidik jari. Selama perkembangannya, masih banyak individu atau orang lain yang bisa mengaksesnya dengan mudah, karena itu kita memerlukan aplikasi untuk membatasi akses dari pihak lain ke gadget kita yang lebih terfokus, sehingga sulit dicabut oleh pihak lain, karena jika pihak lain bisa leluasa mengakses gadget kita itu berarti kita rentan terhadap pencurian data keamananya. Penelitian ini bertujuan untuk menyediakan aplikasi yang bisa memecahkan masalah itu dengan mengunci gadget kita menggunakan pin lock. Walaupun aplikasi pin lock sudah banyak jenisnya, akan tetapi dengan penelitian ini hasil yang dicapai adalah untuk menghasilkan sebuah aplikasi security lock pada smartphone berbasis android yang memanfaatkan tombol angka sebagai pemicu untuk mengunci layar smartphone.
\end{abstract}

Kata Kunci: Aplikasi Security Lock Android, Handphone, Android

\begin{abstract}
These activities will certainly exchange information in them. Therefore smartphones are usually equipped with security features so that information is not spread freely. In this technological era, data security is needed. One way to secure our gadgets is by using application systems such as buttons, pin lock, pattern lock, and fingerprints. During its development, there are still many individuals or other people who can access it easily, so we need an application to limit access from other parties to our gadgets that are more focused, making it difficult to revoke by other parties, because if other parties can freely access our gadget means we are vulnerable to theft of security data. This research aims to provide applications that can solve that problem by locking our gadgets using pin lock. Although there are many types of pin lock applications, but with this research the results achieved are to produce a security lock application on an Android-based smartphone that uses the number keys as a trigger to lock the smartphone screen.
\end{abstract}

Keywords: Security Lock Application, Mobile, Android

\section{Pendahuluan}

Kemajuan teknologi sangat diperlukan dalam pengembangan ilmu pengetahuan serta pembangunan disegala bidang usaha. Maka hal yang perlu diperhatikan adalah tentang penerapan teknologi dan informasi yang 
dapat atau diterima sejalan dengan perkembangan zaman.

Menurut Silvia, Haritman dan Muladi menyatakan bahwa "Android adalah platform open source yang komprehensif dan dirancang untuk mobile devices". Dikatakan komprehensif karena Android menyediakan semua tools dan frameworks yang lengkap untuk pengembangan aplikasi pada suatu mobile device. Sistem Android menggunakan database untuk menyimpan informasi penting yang diperlukan agar tetap tersimpan meskipun device dimatikan (Silvia, Haritman, \& Mulyadi , 2014)

Seiring dengan tingkat mobilitas yang tinggi, beberapa tahun terakhir tengah marak perangkat bergerak atau mobile device. Salah satu perangkat mobile yang paling pesat adalah smartphone berbasis android, dimana hampir setiap orang memilikinya. Android sistem operasi berbasis linux dapat digunakan diberbagai perangkat mobile. Hingga saat ini android terus berkembang baik secara sistem maupun aplikasinya. Banyaknya smartphone android yang diproduksi, menjadikan fitur fitur yang ada didalamnya menjadi semakin berkembang. Salah satu perkembangan yang cukup pesat pada android ialah fitur keamanan, dimana yang awalnya hanyalah berupa pin unlock kini menjadi semakin bervariasi, seperti face unlock, face and voice unlock, dan pattern unlock. Namun, masih terdapat kelemahan pada sistem security yang menggunakan pin unlock, yakni tidak semua versi android dapat menjalankan aplikasi ini. Dengan sistem keamanan yang baik, berbagai macam file penting yang tersimpan di dalam perangkat smartphone dapat semakin terlindungin terhadap kasus pencurian file yang terjadi.

Tujuan Penelitian ini adalah untuk merancang serta membangun aplikasi security lock yang dapat berjalan dengan lancar pada smartphone berbasis android. Sistem ini diharapkan akan mempermudah digunakan oleh pengguna smartphone android. Membuat aplikasi security lock yang mudah digunakan dan dapat dimanfaatkan oleh masyarakat. Membantu masyarakat untuk membuat perangkat smartphone menjadi lebih aman.

\section{Landasan Teori}

Berdasarkan penulis Al-Bahra bin Ladjamudin menjelaskan bahwa Perancangan merupakan suatu kegiatan dengan tujuan untuk mendesain sistem yang baru sehingga dapat menyelesaikan banyak masalah yang terdapat pada sistem di perusahaan sehingga dapat memperoleh alternatif sistem terbaik" (Bin Ladjamudin \& Al Bahra, 2005).

Dapat disimpulkan bahwa rancang bangun adalah suatu penggambaran, perencanaan dan pembuatan sketsa atau pengaturan dari beberapa elemen yang terpisah dan menjadi kedalam satu kesatuan yang utuh dan berguna untuk kegiatan menciptakan yang baru maupun mengganti atau memperbaiki sistem yang ada baik secara keseluruhan maupun sebagian dari sistem tersebut.

Suatu aplikasi dapat berupa subkelas perangkat lunak komputer menggunakan kemampuan komputer langsung untuk mengerjakan tugas sesuai keinginan pengguna. Cara kerja aplikasi ini tentunya sejalan dengan perangkat lunak sistem operasi yang mengintegrasikan berbagai kemampuan komputer.

Menurut Hengky W Pramana mengemukakan bahwa aplikasi adalah satu unit perangkat lunak yang dibuat untuk melayani kebutuhan akan beberapa aktivitas seperti sis-tem perniagaan, game, pelayanan masyarakat, periklanan, atau semua proses yang hampir di-lakukan manusia" (Pramana, 2012)

Android menurut Nazaruddin mengungkapkan bahwa Android merupakan sistem operasi untuk telepon seluler yang berbasis Linux. Sistem Operasi Android bersifat terbuka untuk para pengembang menciptakan aplikasi karya sendiri dan diterapkan banyak macam perangkat bergerak. Android umum digunakan di smartphone dan juga tablet PC". Fungsi android sama seperti sistem operasi Symbian di Nokia, iOS di Apple dan BlackBerry OS (Harahap, 2012).

Menurut Nazaruddin Safaat menyatakan bahwa SQlite adalah salah satu software yang embedded yang sangat popular, kombinasi SQL Inteface dan penggunaan memory yang sangat sedikit dengan kecepatan yang sangat 
cepat. SQLite di android dapat membuat database dengan SQLite" (Harahap, 2012).

\section{Metode Penelitian}

Berdasarkam hasil penelitian sementara kajian teori yang disusun peneliti, maka dapat dibangun suatu kerangka berpikir tentang perancangan seperti yang disajikan di gambar 1.

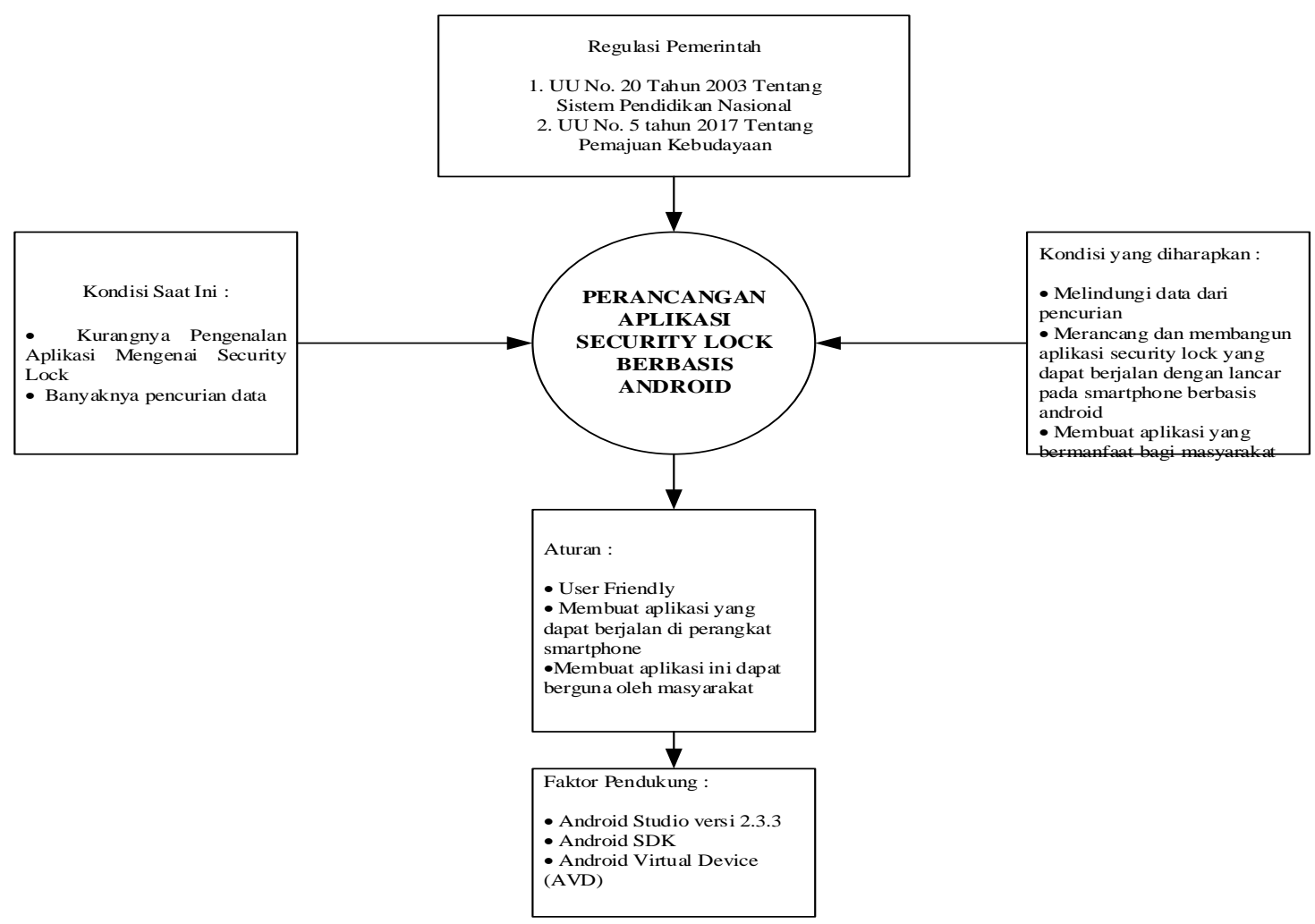

Gambar 1. Kerangka Berpikir

Keterangan Gambar :

1. Regulasi Pemerintah

(a) UU No. 20 tahun 2013 pasal 1 ayat 1dan ayat 21 tentang sistem pendidikan Nasional.

(b) UU No. 5 tahun 2017 Tentang Penerapan Kebudayaan.

2. Kondisi Saat ini

Kurangnya Pengenalan Aplikasi Mengenai Security Lock dan banyaknya pencurian data.

3. Aturan

Berisikan tentang suatu syarat dalam pencapaian hasil yang ditujukan dalam perancangan suatu sistem, dimana dalam pencapaian hasil tersebut harus semaksimal mungkin dapat diterima

4. Faktor Pendukung

- Android Studio versi 2.3.3
- Android SDK

- Android Virtual Device (AVD)

5. Kondisi Yang Diharapkan

- Melindungi data dari pencurian

- Merancang dan membangun aplikasi security lock yang dapat berjalan dengan lancar pada smartphone berbasis android

- Membuat aplikasi yang bermanfaat bagi masyarakat

Dalam Rancang bangun mengenai security lock menggunakan Android, peneliti menggunakan pemodelan waterfall. Pada proses waterfall ditunjukkan metode pengembangan dimana pengembang aplikasi diharuskan mengikuti langkah-langkah pada Gambar 2. 


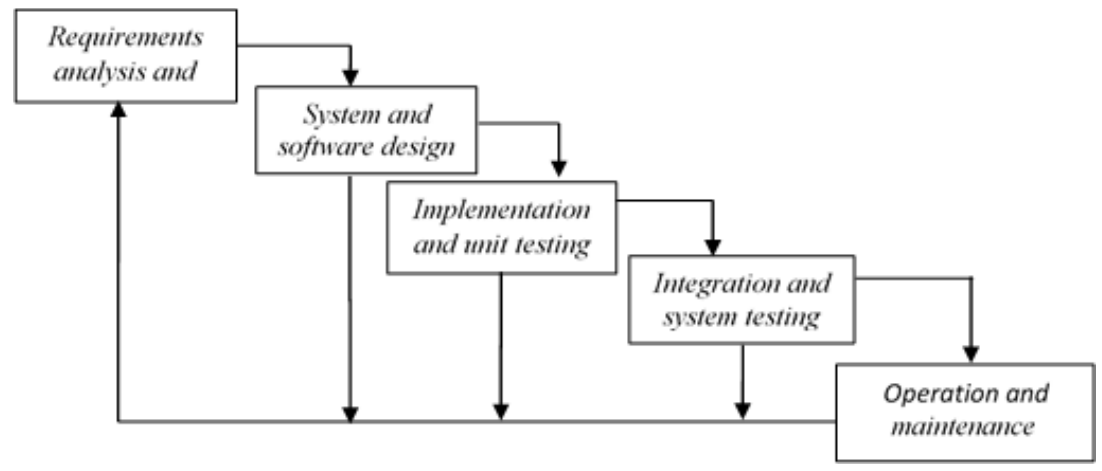

Gambar 2. Permodelan Watefall

Menurut Thomas H. Cormen Algoritma adalah prosedur komputasi yang mengambil beberapa nilai atau kumpulan nilai sebagai input kemudian di proses sebagai output sehingga algoritma merupakan urutan langkahkomputasi yang mengubah input menjadi output (Cormen, 1989)

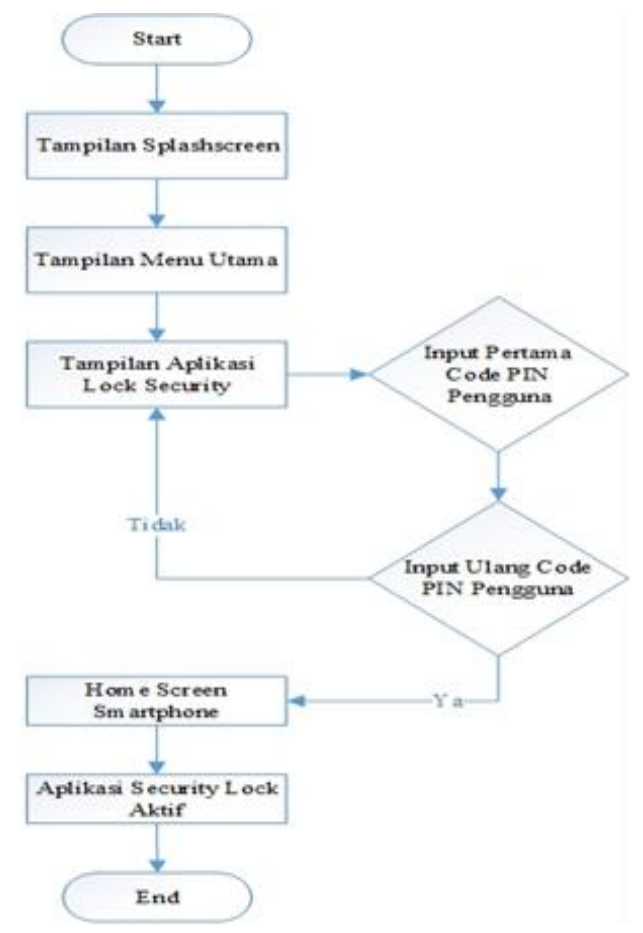

Gambar 3. Algoritma Aplikasi Security Lock

Pada saat aplikasi pertama dijalankan, maka akan menampilkan layar perkenalan seperti splashscreen dan setelah itu langsung menampilkan menu utama program.

1. Splash screen

Tampilan splashscreen tampil selama \pm 2 detik setelah itu tampilan splashscreen akan hilang dan sistem otomatis langsung masuk ke menu utama.

2. Menu Utama

Tampilan pada menu ini yaitu halaman utama dari aplikasi security lock, dimana terdapat tombol dengan tulisan security lock tester yang akan mengaktifkan mode menu penginputan code pin.

3. Menu Input Code Pin

Tampilan pada menu input code pin, dimana terdapat tombol angka $0-9$ dan kolom text password untuk menginput jenis password berupa angka yang ada pada menu utama aplikasi security lock dengan maksimal empat kombinasi angka yang dapat dimasukkan pada kolom text password. Jika angka yang dimasukkan benar, maka home screen pada smartphone akan terbuka dan aplikasi lock screen akan aktif.

4. Menu Lock Screen

Pada tampilan menu lock screen, dimana menu ini akan aktif pada smartphone dalam keadaan sleep setelah pengguna melakukan proses penginputan kode PIN. Ketika pengguna ingin membuka aplikasi ini, cukup dengan menekan icon berbentuk kunci.

Rancangan Tampilan Halaman Depan Menu Utama

Rancangan tampilan halaman depan merupakan menu awal yang pertama kali muncul, terdapat button mulai yang berfungsi untuk masuk ke menu utama dan button tentang untuk masuk ke halaman mengenai informasi peneliti dan cara penggunaan aplikasi. 
- Nama : Halaman Depan

- Fungsi : Menampilkan halaman pertama aplikasi

- Bentuk Tampilan : Lihat gambar 4.

- Proses : Pada halaman depan terdapat satu button, yaitu button Security Lock Tester tester yang akan mengaktifkan mode menu penginputan kode pin.

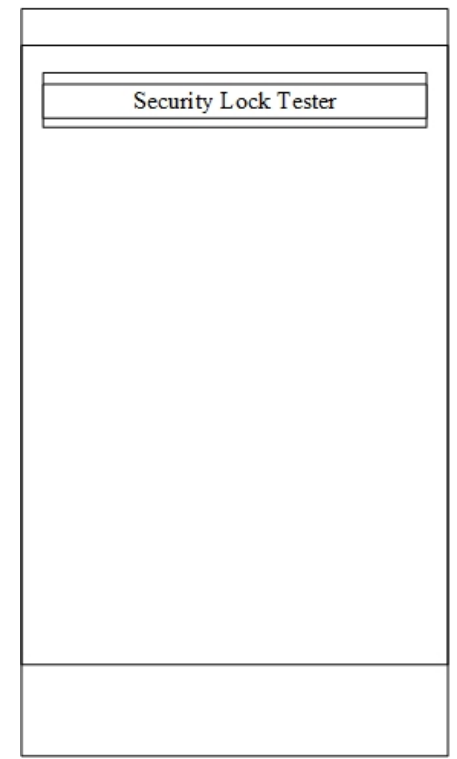

Gambar 4. Rancangan Tampilan Halaman Depan

Rancangan Menu Input Code Pin

Rancangan tampilan Menu Input Code Pin merupakan menu yang menampilkan button angka dari 0 sampai dengan 9 dimana proses penginputan PIN akan terjadi dan akan mengaktifkan sistem pengunci.

- Nama : Halaman Menu Input Code

- Fungsi : Menampilkan halaman untuk memberikan inputan

- Bentuk Tampilan : Lihat gambar 5.

- Proses : Pada halaman menu input ini terrdapat 3 button dan button angka dimana yang berguna untuk memproses penginputan PIN akan terjadi dan akan mengaktifkan sistem pengunci. Setelah itu pengguna diminta kembali untuk memasukkan kode PIN kedua sebagai tanda bahwa kode PIN sesuai dengan yang pertama dimasukkan. Berhasil memasukan kode PIN akan langsung kembali ke menu utama dan mengaktifkan menu lock screen.

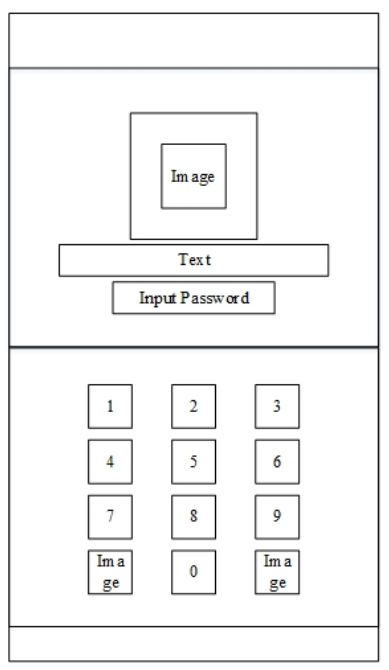

Gambar 5. Rancangan Tampilan Menu Input Code PIN

Rancangan Menu Lock Screen

Rancangan tampilan menu lock screen, dimana menu ini akan aktif pada smartphone dalam keadaan sleep setelah pengguna melakukan proses penginputan kode PIN. Ketika pengguna ingin membuka aplikasi ini, cukup dengan menekan icon berbentuk kunci.

- Nama : Halaman Menu Lock Screen

- Fungsi : Menampilkan Halaman Aktif

- Bentuk Tampilan : Lihat Gambat 6.

- Proses : Pada halaman menu lock screen dimana smartphone dalam keadaan diam ataupun Sleep setelah pengguna ingin membuka kembali aplikasi ini, cukup dengan memberi atau menelan icon yang berbentuk kunci.

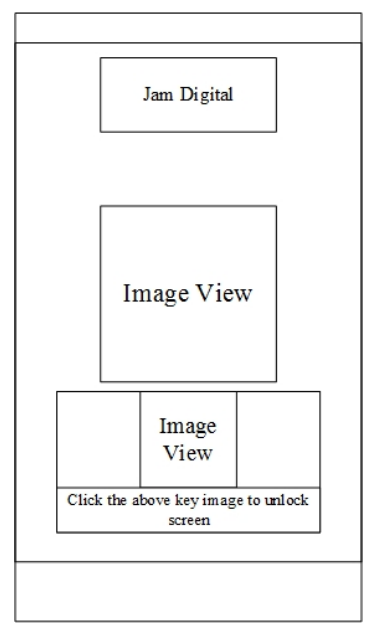

Gambar 6. Rancangan Tampilan Menu Lock Screen 


\section{Hasil dan Pembahasan}

Pembahasan hasil uji coba dari aplikasi Security Lock berbasis Android" yang dibuat oleh Peneliti:

\section{Halaman Depan Menu Utama}

Halaman depan berisi satu button yaitu button mulai yang berfungsi untuk masuk ke menu utama dan button tentang untuk masuk ke halaman mengenai informasi Peneliti dan cara penggunaan aplikasi.

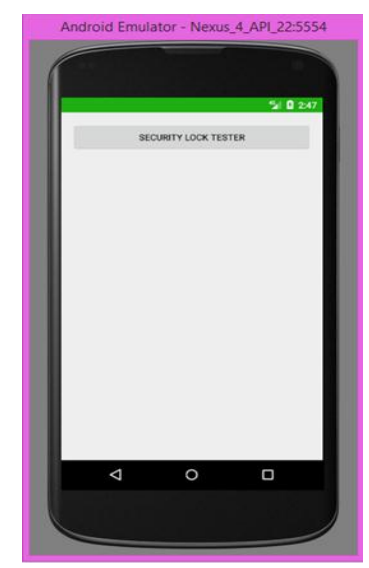

Gambar 7. Tampilan Halaman Menu Utama

\section{Menu Input Code PIN}

Tampilan Halaman menu utama merupakan menu yang menampilkan pengguna wajib menginput kode PIN sesuai keinginan dengan berbagai kombinasi angka yang berbeda beda.

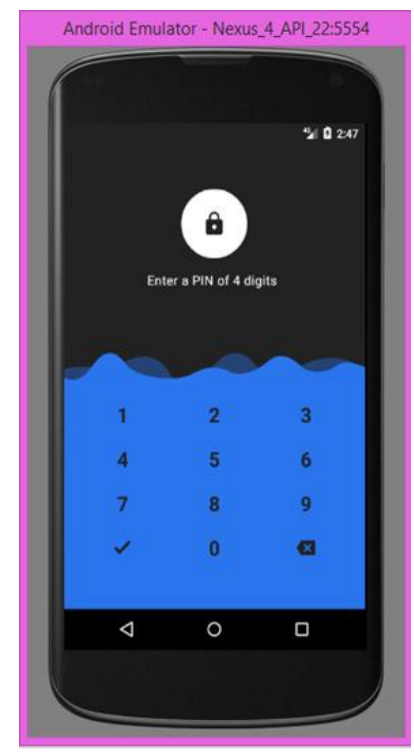

Gambar 8. Tampilan Menu Input Code PIN

\section{Menu Lock Screen}

Pada tampilan menu lock screen, dimana menu ini akan aktif pada smartphone dalam keadaan sleep setelah pengguna melakukan proses penginputan kode PIN pertama dan kedua. Ketika pengguna ingin membuka aplikasi ini, cukup dengan menekan icon berbentuk kunci.

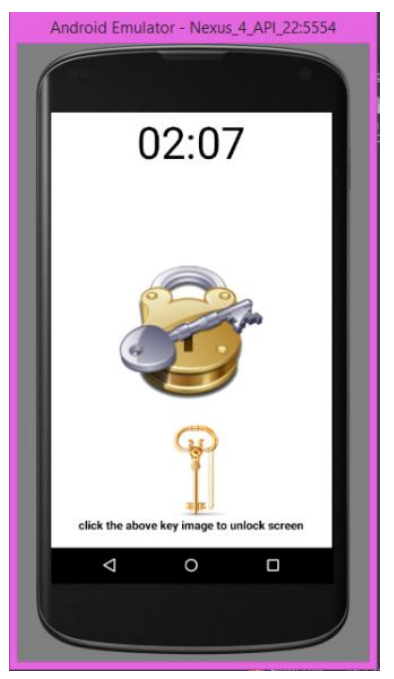

Gambar 9. Tampilan Menu Lock Screen

Pengujian sistem dilakukan untuk mencari kesalahan atau kekurangan pada perangkat lunak yang di uji. Pengujian bermaksud untuk mengetahui perangkat lunak yang dibangun apakah sudah memenuhi kriteria yang dibutuhkan pengguna atau belum.berdasarkan dari uji coba program pada emulator yang disediakan Android Virtual Device (AVD) dan perangkat smartphone android, dapat diperoleh hasil sebagai berikut :

1. Desain yang ditampilkan sangat sederhana

2. Program ini sangat mudah untuk digunakan

3. Perancangan sistem menampilkan 10 digit angka dari $0-9$ dengan menggunakan frame layout PIN sebagai sistem aktivasi pengunci.

\section{Kelebihan dan Kelemahan Sistem}

1. Kelebihan Sistem

Pada bagian ini dapat dijelaskan kelebihan dari aplikasi security lock berbasis android, yaitu : 
a. Tampilan yang sederhana dapat dengan mudah dimengerti pengguna.

b. Aplikasi ini sangat mudah penggunaannya.

c. Aplikasi ini dibuat gratis sehingga semua orang dapat menggunakannya secara bebas.

2. Kelemahan Sistem

a. Kurangnya data dan pengetahuan yang dimiliki penulis tentang bahasa pemrograman android agar sistem dapat dikembangkan lebih baik lagi.

b. Aplikasi ini tidak multi - platform atau hanya dapat berjalan pada perangkat android.

c. Aplikasi ini hanya bisa digunakan dengan operasi sistem android versi 5.0 (Lollipop) ke atas.

\section{Kesimpulan}

Berdasarkan dari pembahasan pada penjelasan sebelumnya dan perumusan penelitian yang ada, maka kesimpulan yang dapat diambil adalah telah berhasil dibangun perancangan aplikasi Security Lock berbasis Android yang bertujuan untuk memudahkan pengguna untuk membuat perangkat smartphone menjadi lebih aman.

Didalam Perancangan Aplikasi security lock berbasis android Salah satu cara untuk mengamankan gadget kita dengan menggunakan sistem aplikasi seperti tombol, pin lock, pattern lock, serta sidik jari. Selama perkembangannya, masih banyak individu atau orang lain yang bisa mengaksesnya dengan mudah, karena itu kita memerlukan aplikasi untuk membatasi akses dari pihak lain ke gadget kita yang lebih terfokus, sehingga sulit dicabut oleh pihak lain, karena jika pihak lain bisa leluasa mengakses gadget kita itu berarti kita rentan terhadap pencurian data keamananya.

\section{Daftar Pustaka}

Bin Ladjamudin, \& Al Bahra. (2005). Analisis dan Desain Sistem Informasi. Tangerang: Graha Ilmu.

Cormen, T. (1989). Introduction to Algorithms. MIT Press.
Harahap. (2012). Pemrograman Aplikasi Mobile Smartphone dan Tablet berbasis Android. Bandung: Informatika.

Pramana, H. (2012). Aplikasi Inventory Berbasis Access 2003. Jakarta: Elex Media Komputindo.

Silvia, A. F., Haritman, E., \& Mulyadi , Y. (2014). Rancang Bangun Akses Kontrol Pintu Gerbang Berbasis Arduino dan Android. ELECTRANS, 1-10. 